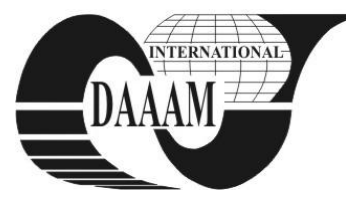

Annals of DAAAM for 2011 \& Proceedings of the 22nd International DAAAM Symposium, Volume 22, No. 1, ISSN 1726-9679 ISBN 978-3-901509-83-4, Editor B. Katalinic, Published by DAAAM International, Vienna, Austria, EU, 2011 Make Harmony between Technology and Nature, and Your Mind will Fly Free as a Bird Annals \& Proceedings of DAAAM International 2011

\title{
FLATNESS OF MECHANICAL INTERFACE OF HOUSING FILTER: COMPARING METHODS
}

HODAK, M[arko]; BARISIC, B[ranimir]; KATALINIC, B[ranko]; KRSULJA, M[arko] \& CAR, Z[latan]

\begin{abstract}
This paper includes investigation of measuring methods for flatness on an aluminum housing filter produced with the procedure of casting. Several methods were taken in consideration for the flatness investigation. Comparison of measurements of flatness has been made, measured with CMM (Coordinate Measuring Machine), marble table and comparator. In this paper we can see that the method of the $C M M$ is the most suitable for measurements in serial production. It can be the only right method for measuring of flatness. The maximum number of point's necessary to achieve quality measurement is analyzed. For measurement purposes made in this paper are used the laboratories of production facilities of the "Cimos" company and laboratory of the Technical Faculty in Rijeka. The results and method are given for further flatness research for this specific part is presented.

Key words: flatness, CMM, measurements, quality, methods
\end{abstract}

\section{INTRODUCTION}

In this paper is made analyses on 30 different parts of oil filter housing from production. In this case the oil filter is mounted on the 1,4 liter diesel engine under a BMW and Citroen license. The housing is made of aluminum alloy and is processed by the client specifications. $\mathrm{AlSi} 9 \mathrm{Cu} 3$ is a universal alloy with very good casting properties and is marked by less affinity to shrinkage. It is a much used universal alloy in die casting for machine and engine parts, cylinder heads, parts for electric engines, etc. Chemical composition of used aluminum alloy ingot is confirmed by thespectrometry with metal analyzer 3460. (Kršulja M. Et al., 2010.).

Comparison of measurements of flatness has been made with different device and methods, measured with CMM, marble table and comparator.

The goal is to select the best method for measuring flatness on motor interface on the body FL:

- $\quad$ flatness is defined in a tolerance size of $0.3 \mathrm{~mm}$. The flatness requirement applies to the entire surface that is also a primary datum $\mathrm{A}$,

- $\quad$ there are not specified additional points for levelling alignment of the drawing,

- $\quad$ according to the DAQF basic measuring method is $\mathrm{CMM}$, in case of problem should be used marble table with control foil or a comparator.

\section{FLATNESS}

Flatness is the one of the most important methods of meteorological measurements. Mathematical definition of flatness for PC-DMIS:

Flatness is based on the least squares solution of the plane. Currently flatness is a common research problem especially for advance production factories (Balbo et al., 2007).

With casting several investigations are usually conducted in order to select the optimal design of the mold shape dimensions and its influence on the final flatness and other dimensional variations (Jiang, \& Xing 2007).

Definition of flatness - According to ISO 1101:
The flatness of a single tolerance feature is deemed to be correct when the feature is confined between both planes, and the distance between them is equal to or less than the value of the specified tolerance. The orientation of the planes shall be chosen so that the maximum distance between them is the least possible value ( Henzold. G., 2006.). In the Fig. 1. is displayed the possible orientation of planes, $\mathrm{h} 1<\mathrm{h} 2$, therefore the correct orientation is $\mathrm{A} 1, \mathrm{~B} 1, \mathrm{C} 1, \mathrm{D} 1$.

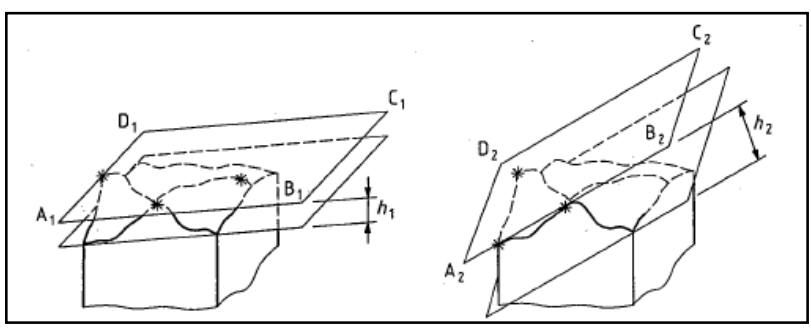

Fig. 1. Possible orientation of planes

\section{MEASURING DEVICES}

\subsection{Measuring with CMM}

CMM (Coordinate Measuring Machine) is a device for measuring the physical geometrical characteristics of an object. This machine may be manually controlled by an operator or it may be computer controlled.

Measurement is made on Global Advantage CMM (HEXAGON -DEA), with analog probe SP25 and software PCDMIS version 2009 MR1

Measurement uncertainty $1.5+\mathrm{L} / 333$ (result in microns; $\mathrm{L}$ in $\mathrm{mm})$. Used stylus tip is $\varnothing 3 \mathrm{~mm}$.

During 2006, because of acquisition a new machine capable of continuing scanning we shift to scanning mode for measuring flatness:

- benefits is in a number of points, that leads to greater accuracy in less time,

- by the request of our customer we modify the trajectories of the scan surface,

- $\quad$ scanning mode - 550 points (before flatness claim 06/2010) , Fig.2.,

- during the analysis of process has been compared differences between two ways of measuring ,Fig.3.

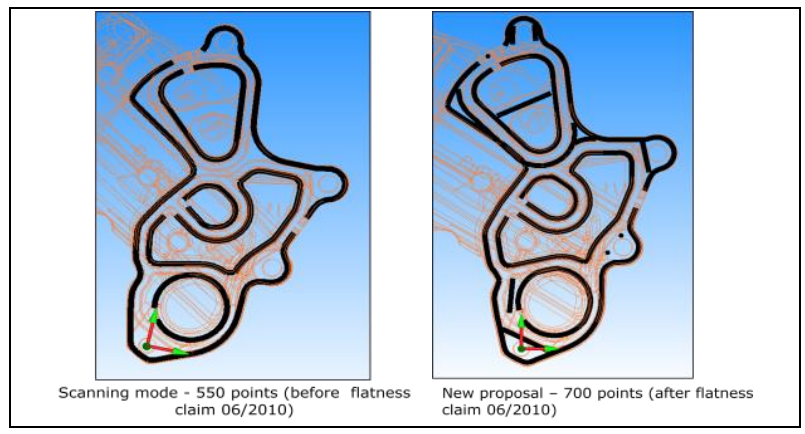

Fig. 2. Scanning mode (before and after flatness claim 06/2010) 


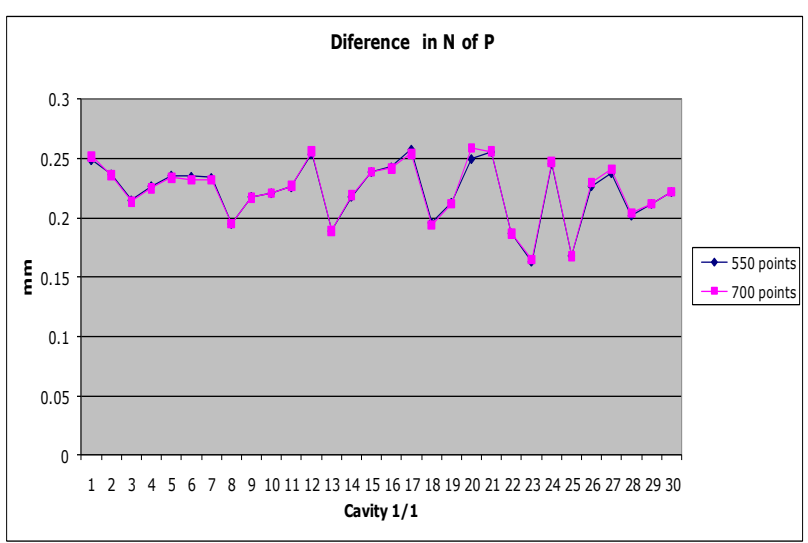

Fig. 3. Number of points have no influence on flatness (550 or 700 points are almost the same flatness like you see on the graph)

\subsection{Measuring on marble table with control foil}

Analyzed tests have some advantages and disadvantages. As advantages we can mention that this method has the advantage that it always rests on the three highest points. Disadvantages are shown as the inaccessibility to certain areas and possibility to reject good parts. Figure 4 . describes that the most parts can be positioned at three different locations.

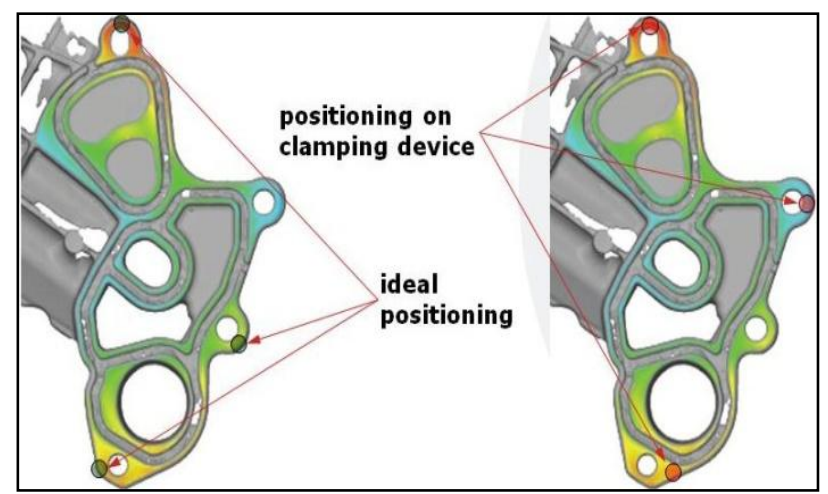

Fig. 4. Ideal positioning and positioning on clamping device

\subsection{Measuring with comparator}

According with Handbook of Dimensional Measurement Third edition, while measuring flatness with comparator the top surface must be parallel with the reference plane, as (Farago et al., 1994).

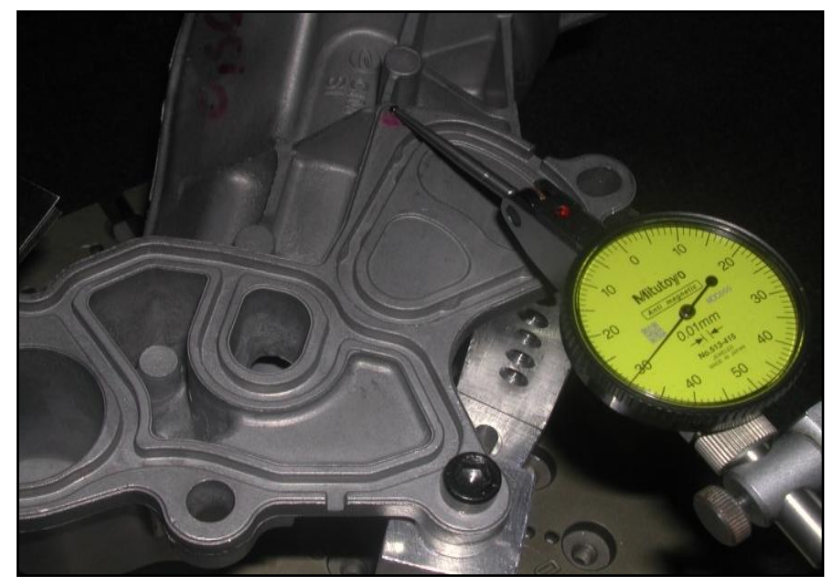

Fig. 5. Measuring with comparator

Misalignment can cause large errors in measurement. It is very important to define 3 highest points equally spaced, that is often problematic in this case for the plane that is long and narrow. Levelling piece in two different ways will give a difference in measurement results. For example we use a part measured in Vire with comparator with a result of flatness $0.560 \mathrm{~mm}$.

In Fig.6. Are the final results of comparing measurements.

\begin{tabular}{|l|c|c|c|}
\hline & CMM & Marble table & Comparator \\
\hline Accuracy & OK & Bad & OK \\
\hline Repeatability & OK & OK & Well \\
\hline Measurement time & Well & OK & Bad \\
\hline Needing specialist & OK & OK & Bad \\
\hline Measuring all points & OK & Bad & OK \\
\hline Measurements report & OK & Bad & Bad \\
\hline Graphical report & OK & Bad & Bad \\
\hline Effort to align & OK & OK & Bad \\
\hline Resolution & OK & Bad & Well \\
\hline
\end{tabular}

Fig. 6. Comparison table (Cimos)

\section{CONCLUSION}

From all of these analyses we can conclude that the CMM method (DEA) is the most suitable for measurements in serial production and can be the only right method for measuring of flatness. For measurement purposes made in this paper are used the laboratories of production facilities of the "Cimos" company and laboratory of the Technical Faculty in Rijeka.

Using a CMM to monitor the flatness of a given casting product has proved to be very useful in keeping a specified quality within a specific tolerance level. CMM is intuitive and easy to use it provides an effective method for maintaining of specified tolerances and enables detection of possible errors in the thickness and control of the production process. With a demonstrated technique we have shown that a lesser number of measurement points can be used with the same quality result in determination of conditioning parameters.

\section{ACKNOWLEDGEMENTS}

The authors would like to acknowledge the support provided by the National CEEPUS Office of Croatia and National CEEPUS Office Austria, which helped the research through mobility in the frame of the CEEPUS II HR 0108 project.

\section{REFERENCES}

Antonio R. Balbo, Edméa Cássia Baptista, Marcos Nereu Arenales (2007). An adaptation of the dual-affine interior point method for the surface flatness problem, European Journal of Operational Research, Volume 181, Issue 3, September 2007, pp. 1607-1616

Farago Francis T. (1994.) Handbook of Dimensional Measurement, Third Edition (1994.)

Henzold. G., (2006.) Geometrical Dimensioning and Tolerancing for Design, Manufacturing and Inspection, A Handbook for Geometrical Product Specification using ISO and ASME standards, second edition (2006.)

Jiaren Jiang, Xing Yang Liu, (2007). Dimensional variations of castings and moulds in the ceramic mould casting processs, Journal of Materials Processing Technology, Volume 189, Issues 1-3, July 2007, pp. 247-255

Kršulja M.; Barišić B.; Plančak M.; Čep R. (2010). Investigation of alluminium alloy composition AlSi9Cu3 alloy in foundury process, Technological Engineering. vol. 7 (2010), 2; 53-56. ISSN 1336-5967

*** www.cimos.eu, site accessed 2011, private documents from Cimos company Buzet, Croatia 